\title{
DESIGN OF ASSEMbLy SYSTEM - MiXed REALITY MODELLING
}

\author{
Peter Malega \& Jozef Kovac
}
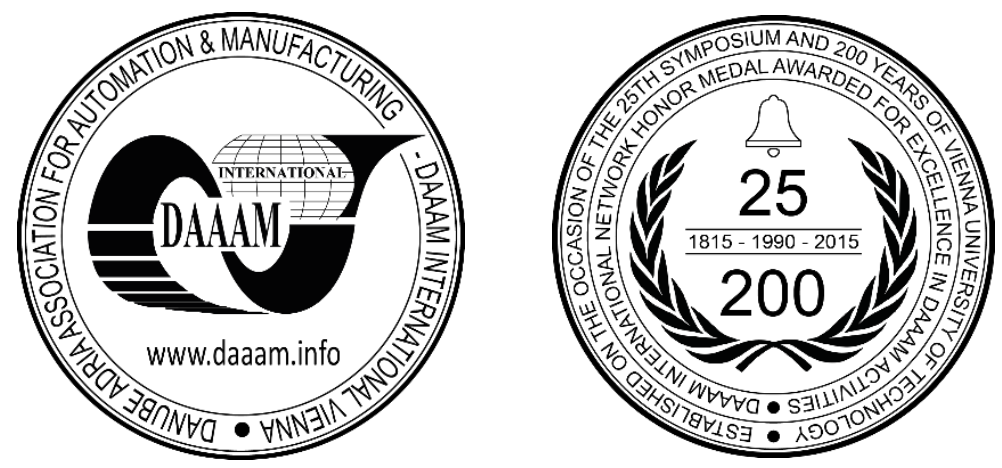

This Publication has to be referred as: Malega, P[eter] \& Kovac, J[ozef] (2016). Design of Assembly System Mixed Reality Modelling, Proceedings of the 27th DAAAM International Symposium, pp.0289-0297, B. Katalinic (Ed.), Published by DAAAM International, ISBN 978-3-902734-08-2, ISSN 1726-9679, Vienna, Austria DOI: $10.2507 / 27$ th.daaam.proceedings.043

\begin{abstract}
Within production system designing are important especially these activities: philosophic and conceptual aspects of technological innovation, modelling, existing solutions certified in praxis, financial and material security of innovation changes and multi-purpose and purpose innovation projects. The aim of every project is optimal reduction of designing processes by simultaneous observance of required quality and costs minimisation. Nevertheless it is important to use innovation methods, tools and procedures within solving the various designing problems. This article is oriented on the designing of assembly system through the interconnection of virtual reality and physical reality. The result of this connection is mixed reality, which can be used as a useful tool in the $21^{\text {st }}$ century.
\end{abstract}

Keywords: design; assembly system; mixed reality; 2D and 3D modelling.

\section{Introduction}

In the present time, innovation methods, practices, tools as well as modern technical and software equipment significantly influence the area of assembly systems design. Contemporary development in this area is affected mainly by progress, which is achieved in modelling of simulation, information, communication and computer technologies [1, $2,18,22]$.

Production systems are converted into finished production processes and the most important representative of these systems is assembly [3, 4, 38, 39].

Design of assembly system despite the achievement progress requires another integrated development and enhancement about new principles and solutions.

Within assembly system design are important especially these activities: philosophic and conceptual aspects of technological innovation, modelling, existing solutions certified in praxis, financial and material security of innovation changes and multi-purpose and purpose innovation projects $[5,9,13,32]$.

Verification and tested software CAx systems will allow creation of digital models of assembly system and their simulation verification in virtual reality, which allows to optimize designing processes and to reduce risks of nonoptimized proposals $[6,10,16,41]$.

New algorithmic procedures of assembly system design on the base of mixed reality modelling supported with CAx technologies originate primarily as the consequence of experimental verification implication [15, 22, 23, 42, 43]. 


\section{Theoretical support of innovative design}

The philosophy of innovative, alternative, interactive and participatory design is based on the assumption that the solution of the assembly system has three stages [8, 10, 16, 24, 40]:

1. It is proposed the initial set of assembly system of variant solutions in line with created goals. It can be used various methods for determining the variants of solution (analytic, morphological, hierarchical generation, usage of reference solutions, etc.). In the case of less complex tasks it can be used the intuitive concepts of generating the variants on the base of the reference type models.

2. It is defined acceptable solutions and excluded the inappropriate variants of solution for assembly system either on the base of the intuitive approach, respectively on the base of usage of logical and mathematical methods.

3. It is selected the optimal variant of assembly system solution as the final stage. There are applied also the decision-making methods, respectively optimization criteria. Optimal variant can be obtained on the basis of comparative methods (reference projects), on the basis of simulation activity, etc.

Illustration of the approach to the design of assembly systems in accordance with this philosophy is shown in Fig.1 $[14,15,18,26,33,39]$.

Innovative design of assembly systems currently uses modelling in all stages of solution and it is supported with the software products.

The importance of assembly system modelling is important for the development of new approaches in designing and optimizing their solutions. Current development trends in the production companies that lead to quickly "adapt to market" structures require their adaptability to all hierarchical levels of design and implementation [17, 29, 32, 35].

Used hierarchical decomposition on the individual levels of solution enables optimization of project assembly structure. This is done in the related detailed activities of the projected process. As the basic construction units are considered autonomous assembly modules. Assembly systems of higher rank are created from these modules [12, 18, $31,33,37]$.

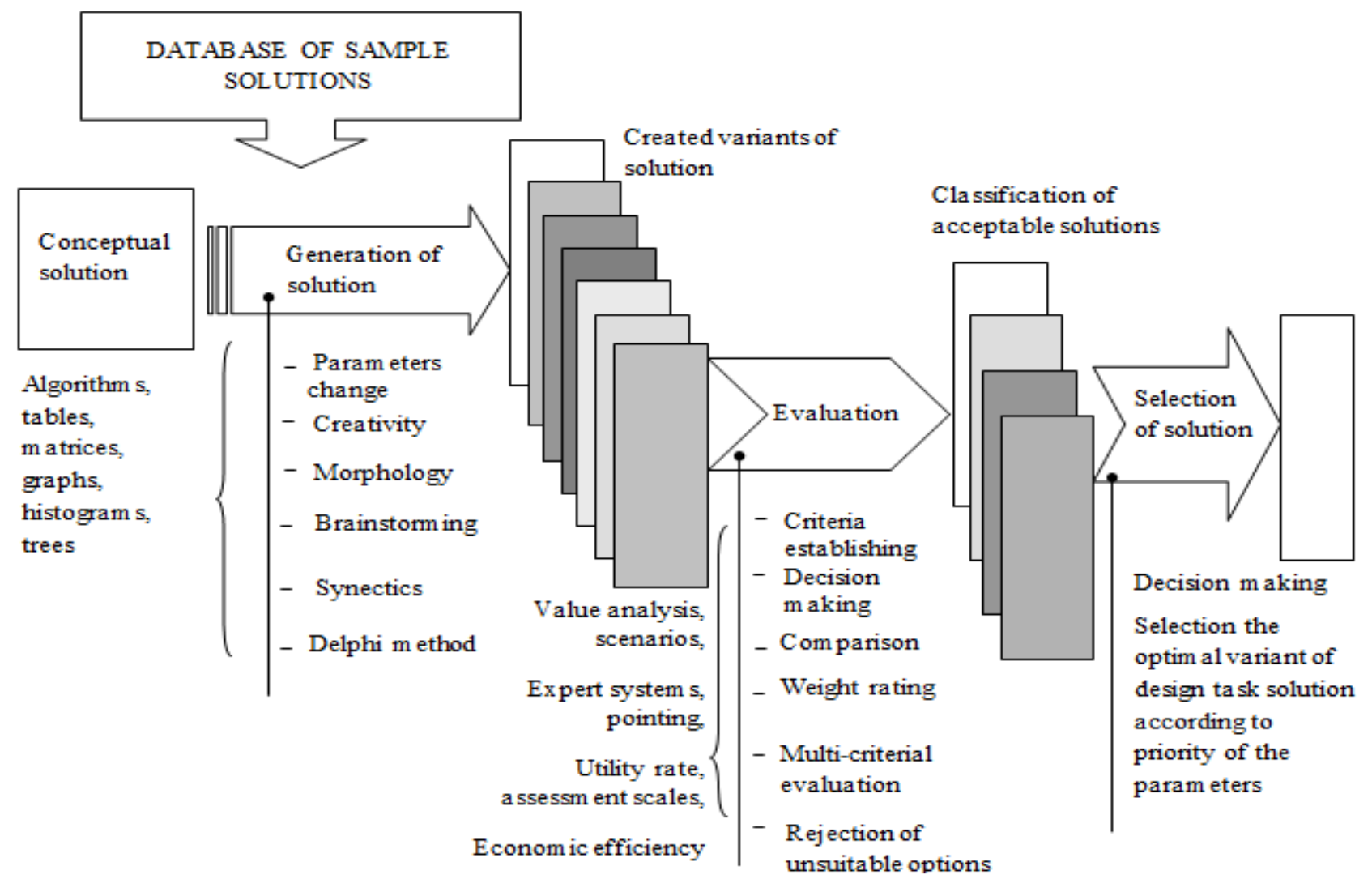

Fig. 1. Illustration of the approach to creating design solutions of assembly systems

\section{Methodical procedure of assembly process modelling}

The methodological procedure algorithm of model creation of assembly system is shown in Fig. 2 [32, 34, 38]. 


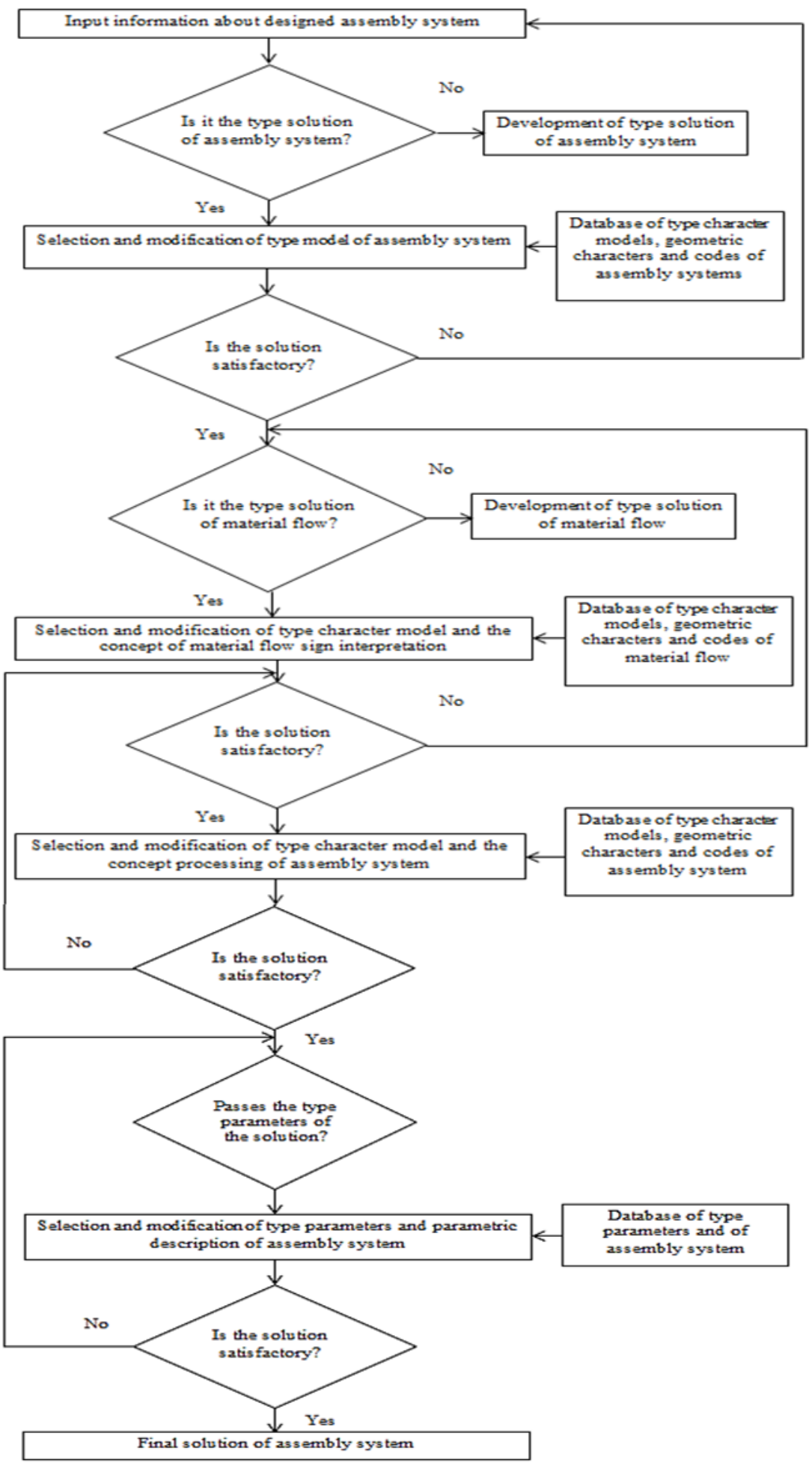

Fig. 2. The methodological procedure algorithm of model creation of assembly system

Methodical procedure of assembly processes modelling and their implementation systems can be divided into four levels $[21,27,37,40]$ :

- At the first level, it is created a conceptual model for assembly process solving. The conceptual model expresses the principled scheme of assembly process and determines the composition and sequence of implemented stages. At this level of modelling it is appropriate to create several variants of symbolic functional structures of assembly process, especially if the optimal sequence sub-processes implementation is a precondition for the effectiveness of the entire solution. Graphic presentation of the conceptual model in this case shows the distribution of assembly workplaces and systems, which implements partial or complete sections of assembly process and material flows. On a similar principle, especially in the design of automated production, are modelled information flows. As information tool for generating variants of conceptual symbolic models may be used reference solutions and project types. 
- At the second level are created models of assembly operations (processes) and models of the functional activity of production workplaces and systems. Models are oriented on composition and sequence of operations (functions) implemented in all operations and operational activities at the workplace, respectively in the system. If the model is oriented not only on the functional activity, but also on the technical conception, there are specified technical units and tools. Decomposition of the functional activity can be implemented into the micro level corresponding, especially to the movements of elements or units. The result of this stage of modelling is again a number of variants from which is then selected optimal variant within the selected decision-making and optimization method.

- At the third level it is implemented parametric description of models. At this level of solution, are quantitative parameters assigned to individual functions (time characteristics, ranges, speed of movements, etc.). The necessary condition is that these parameters are specified in preceding stages of the design solution, or in the reference patterns.

- At the fourth level are elaborated spatial and time charts. These charts reflect the spatial and motion functions performed with the implementation tools, as well as corresponding time dependences.

\section{Creating of virtual reality in laboratory conditions}

In our laboratories were realized several kinds of laboratory experiments with appropriate laboratory equipment [3, $4,5,6,26,31]$.

\section{a. Integrated laboratory of managerial and project system \\ This laboratory includes:}

Horizontal design table (work with project table - Fig. 3) designed for creating 3D physical models of the assembly system concepts and plants, including planning and managing their activities. It enables teamwork of different specialists. It uses the 3D models of construction equipment (machines, robots, vehicles, etc.) for generating variants of production systems in appropriate scales.

Digital camera system is used for capturing and digitizing the projected assembly system (scenes) for the CA technologies treatment.

2D presentation system displays 2D conceptual computer generated scenes on project table.

PC system with CA technologies is used for the assembly of digital and virtual projects at conceptual level and detailed level including their simulation verification (DELMIA software modules for the design of digital factories, respectively other CA systems).

3D (2D) is used as presentation system for displaying virtual project scenes.

Virtual technical equipment (data glove, helmet display, 3D projector, etc.) is used for generating of the work in virtual reality, e.g. assembly.

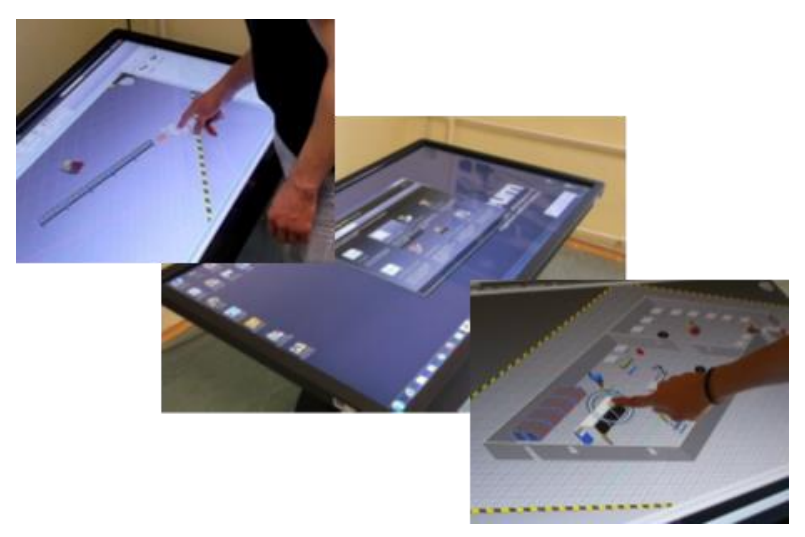

Fig. 3. Work with project table

It enables the new form of interaction between the computer and the designer. Multitouch technology combines display technology with sensors that are able to watch more entry points. The technology lets users the interaction with computers.

The device is used for visualization and manipulation of objects in virtual reality. For the implementation and sensing of Multi-Touch points is used the applications CCV (multitouch open-source framework).

b. Department of virtual reality

It consists from modern hardware and software equipment that supports work in virtual reality.

Data gloves CyberGlove II (right and left) sense the spatial movement with 18 high-precision measurement sensors. They use patented resistive technology for accurate transformation of hand and finger moves in real-time data [23, 24, $25]$. 
Wireless glove CyberGlove (Fig. 4) from Immersion Corporation is equipped with 18 sensors that detect movement of the fingers and hand. It uses a precise and sensitive motion technology to fingers and hands in real space and transmits them in to the virtual space.

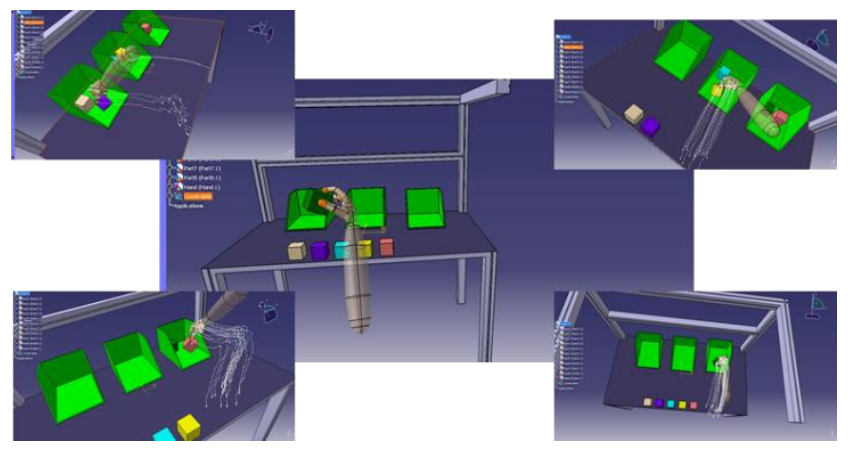

Fig. 4. Cyber Glove II - physical movements of data glove in the virtual reality

The basic system includes a glove, 2 batteries, battery charger and USB wireless adapter with drivers [30].

Sensing runs under magnetic method. It uses sensors that are clamped to the glove. They respond to low frequency magnetic field generated by the source. The computer then analyses the given location and movement in a magnetic field and this motion is transferred into the 3D environment in which the device operates. Sensing of the hand position in space provides "track" facility. Ascension Flock of Birds is a device that captures and transmits the behaviour of the motion sensor to the computer. Flock consists of the device itself, transmitter and motion sensor, which is mounted on the wrist. Connection is made via the serial $\mathrm{RS}-232 \mathrm{C}$ port.

\section{c. Computer network}

Computer network with hardware and software for virtual reality modelling is equipped with 2 workstations, 5 specialized PC (CA), 10 classic PC stations with the accessories, CAD and other specialized software. Software modules of the DELMIA allow virtual 3D productions. Development and validation of production processes is in the connection to the product in all its development stages. Academic license includes the whole portfolio of solutions DELMIA.

DELMIA PLM Express is used in the laboratory conditions primarily for digital plant solution in the small and medium enterprises. Human Work Analysis is used for simulation and ergonomic analysis of the human body in the production environment and the factors that act on it. It includes modules Workplace Simulation (HSU), Human Catalogues (HCU) and Human Work Analysis (HAU).

For the valuation of human physical activities in non-automated work activities are used the function RULA. Setting the parameters and analysis results are displayed in the dialog boxes and tables. In the score section of the RULA analysis dialog window shows partial results, respectively burden assessment of body parts and the resulting evaluation score. $[19,20]$ 3D model with ergonomic analysis and 3D animation of selected workplace are shown in Fig. 5 [16, $17]$.

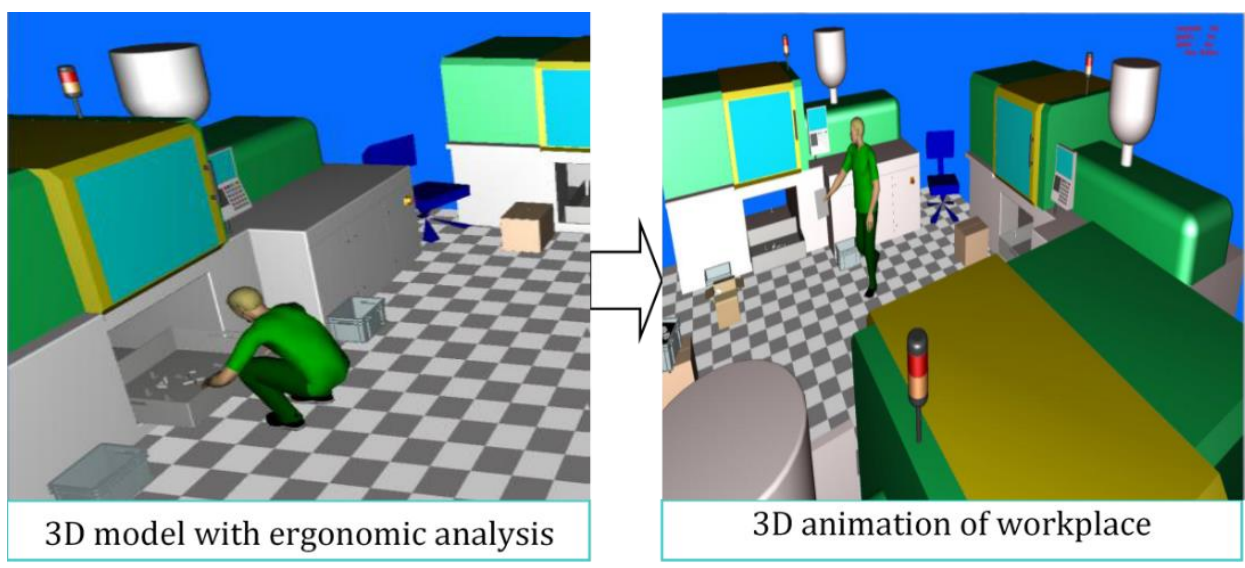

Fig. 5. 3D model with ergonomic analysis and 3D animation of workplace

On this workplace were realized RULA analyses.

The final score can have a value from 1 to 7 and is also expressed in colour. The meaning of several values is following: 
- 1 and 2 (green) - indicates, that the posture can be accepted under the assumption, that it is not the same for a long time or it is not often repeated for a long time,

- 3 a 4 (yellow) - indicates the need of further detailed research and then, maybe be necessary to change the postures,

- 5 a 6 (orange) - indicates, that the research and the changes are necessary in very short time,

- 7 (red) - indicates, that is necessary immediate to research and to change of the postures.

This final score is accounted as a middle value from the partial scores of the particular body parts. For every body part exist a separate evaluating scale (see Table 1).

\begin{tabular}{|l|l|l|l|l|l|l|l|}
\hline $\begin{array}{l}\text { Segment }- \text { part } \\
\text { of body }\end{array}$ & Score & 1 & 2 & 3 & 4 & 5 & 6 \\
\hline Upper arm & $\begin{array}{l}\text { from } 1 \\
\text { to 6 }\end{array}$ & Green & Green & Yellow & Yellow & Red & Red \\
\hline Forearm & $\begin{array}{l}\text { from } \\
\text { 1to } 3\end{array}$ & Green & Yellow & Red & & & \\
\hline Wrist & $\begin{array}{l}\text { from } \\
1 \text { to } 4\end{array}$ & Green & Yellow & Orange & Red & & \\
\hline Wrist twist & $\begin{array}{l}\text { from } \\
\text { 1to } 2\end{array}$ & Green & & & & & \\
\hline Neck & $\begin{array}{l}\text { from } \\
\text { 1to 6 }\end{array}$ & Green & Green & Yellow & Yellow & Red & Red \\
\hline Trunk & $\begin{array}{l}\text { from } \\
\text { 1to 6 }\end{array}$ & Green & Green & Yellow & Yellow & Red & Red \\
\hline
\end{tabular}

Table 1. Realized RULA analysis

\section{Creating of physical reality in laboratory conditions}

On the basis of virtual reality, we made experiments also in physical reality. This research was made according to results from virtual reality and on this research it was used the physical equipment of our laboratories. View of the experimental work carried out by the data glove is shown in Fig. 6 [33, 39].

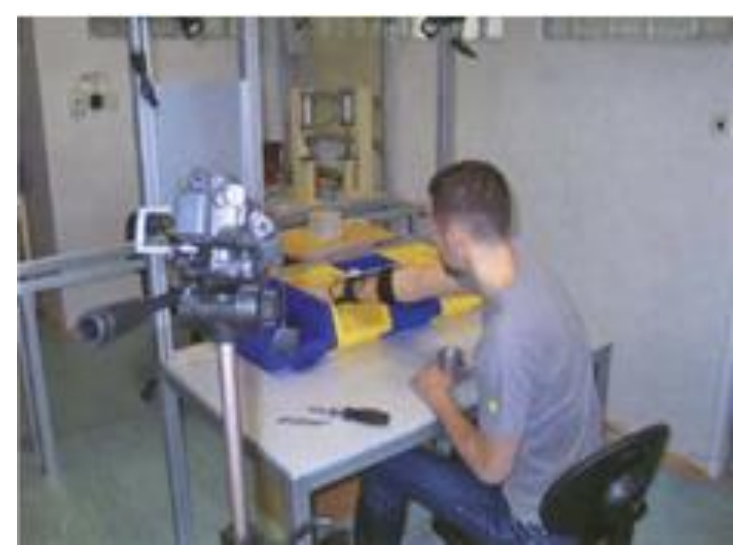

Fig. 6. Physical realization of work by data glove

During the realization of work (e.g. assembly) are sensed the hand movement trajectories with the data glove. Implemented movement is recorded and displayed in virtual reality on a computer terminal screen of workstation. Each trajectory corresponds with the motion of data glove sensor $[35,36]$.

\section{Creating of mixed reality in laboratory conditions}

In terms of the assembly system conception and its spatial structure are innovative practices based on the mixed reality modelling of assembly systems particularly effective in the development of assembly clusters of higher rank [7, $9,28,40,41,42,43]$.

Manipulation with physical model through virtual hand is shown in Fig. 7 [11, 25, 31].

This is the result of our research, where we found interconnection between virtual and physical reality in laboratory conditions and we have shown and also we believe, that mixed reality is the future of the innovative design of assembly 
systems. This mixed reality has advantages from two areas (physical and virtual reality) and it puts them into one bigger reality, named mixed reality.

Our results can be also interpreted as an experiment, in which we tried to find the basis for the future research in the area of innovative design of assembly systems, because in the mechanical engineering area is still the place for improvements, which will people use in various areas of their life as a useful tool in the $21^{\text {st }}$ century.

So, we can state, that our hypothesis about mixed reality was correct and we found the connection between virtual and physical reality and we tested it in real conditions and results show the exploitability of this tool in the $21^{\text {st }}$ century.

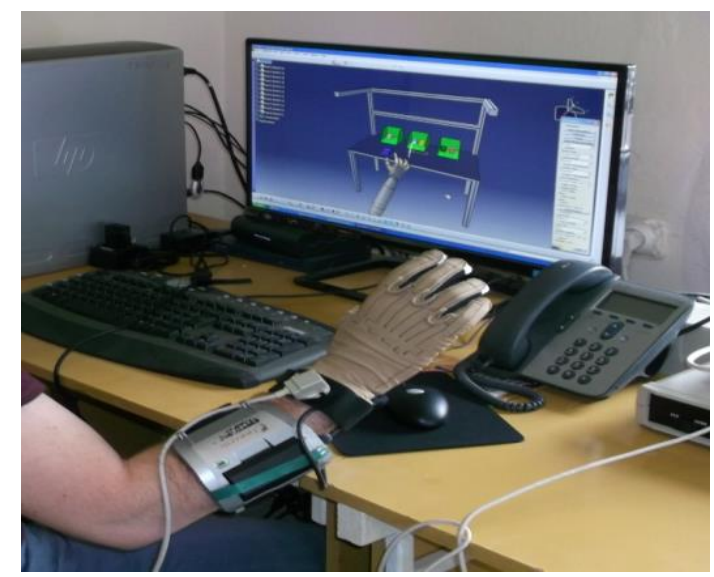

Fig. 7. Transformation of physical movements of data glove into the virtual reality

\section{Conclusion}

Assembly system conceptions projected as the new generation systems represents complex integrated solutions created on the basis of exploitation modern software, information and communication technologies $[1,18,24,40]$.

Technical and software tools contribute to increasing of productivity, projection activities, quality, products and services value and decreasing of assembly time [6, 14].

The problem was to create innovative design of assembly systems in the area of mixed reality, which is in today's competitive environment one of the biggest challenge for the industrial companies. We proposed the methodological procedure algorithm of model creation of assembly system, which we can use as a scheme for our research today and also in the future. Then we put all inputs in the virtual reality, in which we realized our research. After modelling in the virtual reality, we focused on the creating of physical reality and in the final stage we focused on the transformation of virtual and physical reality into the mixed reality and in this area we modelled the assembly systems. So, in the laboratory conditions, we found the interconnection between virtual and physical reality and the creation of mixed reality as the result of our research will help us in the future research, which we have to focus on the modelling of assembly systems, but not only in the laboratory conditions. Our vision is to help small and medium industrial enterprises to see their future possibilities in the area of assembly systems modelling.

\section{Acknowledgments}

This article was created by implementation of the grant project VEGA 1/0853/16 "New project technologies for the creation and implementation of future factories".

\section{References}

[1] Abele,T. (2006) Verfahren fúr das Technologie-Roadmapping zur Unterstútzung des strategischen Technologiemanagements. JostJetterVerlag, Heimsheim

[2] Bandic Glavas, M. \& Majstorovic, V.: Future Virtual Project Management Development Trends, Annals of DAAAM for 2012 \& Proceedings of the 23rd International DAAAM Symposium, ISBN 978-3-901509-91-9, ISSN 2304-1382, pp 1159 - 1162, Editor Katalinic, B., Published by DAAAM International, Vienna, Austria

[3] Erler, M. \& Essers, M. (2012) Approach for Generation of Complete Virtual Machine Tools based on a Unified Model Description, Annals of DAAAM for 2012 \& Proceedings of the 23rd International DAAAM Symposium, ISBN 978-3-901509-91-9, ISSN 2304-1382, pp 0779 - 0782, Editor Katalinic, B., Published by DAAAM International, Vienna, Austria

[4] Cheng, H. et al. A virtual reality-based system for hand function analysis. // Computer Methods and Programs in Biomedicine. Vo. 69, No. 3 (2002), pp. 189-196. ISSN 0169-2607 
[5] Cheng, Y., Huang, R. (2012) Using virtual reality environment to improve joint attention associated with pervasive developmental disorder. // Research in Developmental Disabilities. Vol. 33, No. 6 (2012), pp. 2141-2152. ISSN 0891-4222

[6] Choi, S.H., Chan, A. M. (2004) A virtual prototyping system for rapid product development. // Computer-Aided Desing. No.. 36, Vol. 5 (2004), pp. 401-412. ISSN 0010-4485

[7] http://www.daaam.info/Downloads/Pdfs/proceedings/proceedings_2015/039.pdf, D DAAAM International Symposium 2015, Accessed on: 2015-11-13

[8] http://www.daaam.info/Downloads/Pdfs/proceedings/proceedings_2015/107.pdf, DAAAM International Symposium 2015, Accessed on: 2015-11-13

[9] http://www.daaam.info/Downloads/Pdfs/science_books_pdfs/2012/Sc_Book_2012-019.pdf, International Symposium 2012, Accessed on: 2012-11-18

DAAAM

[10] http://www.sciencedirect.com/science/article/pii/S1877705814002021, DAAAM International Symposium 2014, Accessed on: 2014-12-09

[11] http://www.sciencedirect.com/science/article/pii/S1877705815004464, DAAAM International Symposium 2014, Accessed on: 2014-12-09

[12] http://www.sciencedirect.com/science/article/pii/S187770581500449X, DAAAM International Symposium 2014, Accessed on: 2014-12-09

[13] Kim, Y., Park, J. (2014) Study on interaction-induced symptoms with respect to virtual grasping and manipulation. International Journal of Human-Computer Studies. Vol. 72, No. 2 (2014), pp. 141-153. ISSN 1071-5819

[14] Kováč, J. et al (2011) Integrated Design manufacturing systems based on physical and virtual modelling. Acta Mechanica Slovaca. Vol. 14, No. 2 (2011), pp. 41-47. - ISSN 1335-2393

[15] Kováč, J., Knežo, D., Ižaríková, D. (2011) The model of topological relations-relation between two constructed equipment. Acta Mechanica Slovaca. Vol. 15, No. 2 (2011), pp. 60-68. - ISSN 1335-2393

[16] Kováč, J., Rudy, V., Kováč, Ju. (2008) Creation of 3D models of production systems and clusters. // Transfer inovácií Vol. 10, No. 11 (2008), pp. 261-264. The web version <http://web.tuke.sk/sjf-icav/stranky /transfer/82005/pdf/261-264.pdf>

[17] Kováč, J., Szombathyová, E. (2006) Ergonomics principles of assembly systems projection. // CO-MAT-TECH 2006. Bratislava : STU in Bratislava, 2006, pp. 593-597. ISBN 80-227-2472-6

[18] Kováč, M., Kováč, J. (2011) Innovative designing of production processes and systems. Košice : TU-SjF, 2011. ISBN 978-80-553-0805-0

[19] Kwon, O. et al. (2009) Determination of key dimensions for a glove sizing system by analysing the relationships between hand dimensions. Applied Ergonomics. Vol. 40, No. 4 (2009), 2008, pp. 762-766. ISSN 0003-6870

[20] Lee, K.-S., J, M.-Ch. (2015) Ergonomic Evaluation of Biomechanical Hand Function. Safety and Health at Work. Vol. 6, No. 1 (2015), pp. 9-17. ISSN 2093-7911

[21] Madarász, L., et al. (2002) Implementation of symbolic modelling in generation of production processes and systems for customer oriented production. RAAD 2002. Budapest : Polytechnic, 2002 pp. 391-395. - ISBN 963715-409-4

[22] Malega, P., Mihok, J. (2006) Downtimes and losses versus effectiveness of production // Transfer inovácií Vol. 8, No. 9 (2006), pp. 97-100. The web version <http://web.tuke.sk/sjf-icav/stranky/transfer/9-2006/PDF/97-100.pdf>.

[23] Malloy, M. K., Milling, S. L. (2010) The effectiveness of virtual reality distraction for pain reduction: A systematic review. Clinical Psychology Review. Vol. 30, No. 8 (2010), pp. 1011-1018. ISSN 0272-7358

[24] Mareš, A., et al. Virtual reality - application of data glove in the solution of selected tasks. Success: productivity and innovation in context. No. 4 (2010), pp. 10-12. ISSN 1803-5183

[25] Mareš, A., et al. Data glove - intuitive tool of handling objects in CAD. IT CAD. Vol. 19, No. 4 (2009), pp. $30-31$. - ISSN 1802-0011 The web version http://www.cad.cz

[26] Mujber, T. S. et al. Virtual reality applications in manufacturing process simulation. Journal of Materials Processing Technology. Vol. 155-156, 2004, pp. 1834-1838. ISSN 0924-0136

[27] Novak - Marcincin, J.; Barna, J.; Fecova, V. \& Novakova - Marcincinova, L. (2012) Augmented Reality Applications in Manufacturing Engineering, Annals of DAAAM for 2012 \& Proceedings of the 23rd International DAAAM Symposium, ISBN 978-3-901509-91-9, ISSN 2304-1382, pp 0065 - 0068, Editor Katalinic, B., Published by DAAAM International, Vienna, Austria, 2012

[28] Nomura, J., Sawada, K. (2001) Virtual reality technology and its industrial applications. Annual Reviews in Control. Vol. 25, 2001, pp. 99-109. ISSN 1367-5788

[29] Ostertagová, E., Kováć, J., Malega, P. (2011) Application of morphological analysis by selection of material flow structure and storage allocation to production system. 1 electronic optic disk (CD-ROM). MMaMS 2011 : Modelling of Mechanical and Mechatronical Systems : proceedings of the 4th international conference : Herl'any, Slovakia, 20. - 22. 9. 2011. Košice : Technical University, 2011 pp. 374-379. ISBN 978-80-553-0731-2

[30] Pilacidi, G. et al. (2013) Overall design and implementation of the virtual glove. Computers in Biology and Medicine. Vol. 43, No. 11 (2013), pp. 1927-1940. ISSN 0010-4825 
[31] Robinson, G. et al. (2009) Automated design process modelling and analysis using immersive virtual reality. Computer-Aided Design. Vol. 41, No. 12 (2009), pp. 1082-1094. ISSN 0010-4485

[32] Rudas, I., J. (1999) CA - system for preparation of production base modernization. Proceedings of the jubilee international conference. Budapest., 1999. pp. 173-176. ISBN 9-637-154-03-5

[33] Saggio, G. (2014) A novel array of flex sensors for a goniometric glove. Sensors and Actuators A: Physical. Vol. 205, 2014, pp. 109-125. ISSN 0924-4247

[34] Siddique, Z., Rosen, D. (1997) A virtual prototyping approach to product disassembly reasoning. Computer-Aided Desing. Vol. 29, No. 12 (1997), pp. 847-860. ISSN 0010-4485

[35] Spear, B. (2002) Virtual reality: patent review. World Patent Information. Vol. 24, No. 2 (2002), pp. $103-109$. ISSN 0172-2190

[36] Steffan, R. - Schull, U., Kuhlen, T. (1998) Integration of virtual reality based assembly simulation into CAD/CAM environments. Industrial Electronics Society, Aachen, Germany, 1998. IECON '98. Proceedings of the 24th Annual Conference of the IEEE, pp. 2535-2537 Vol.4, ISBN 0-7803-4503-7

[37] Svoboda, M., Senderská, K., Kováč, J. (2004) Assembled product analysis as a part of assembly systems design procedure. Acta Mechanica Slovaca. Vol. 8, No. 1 (2004), pp. 91-96. - ISSN 1335-2393

[38] Straka, L. (2005) New Trends in Technology System Operation. Proceedings of the 7th conference with international participation, Presov, pp. 385, 2005

[39] Šutaj-Eštok, A., Liberko, I., Sirková, M. (2012) Process management in relation to the systems thinking. In: Management 2012 : research management and business in the light of practical needs. - Prešov : Bookman, 2012. p. 214-218. ISBN 978-80-89568-38-3

[40] Wang, Q.-H., Li, J.-R. (2006) Interactive visualization of complex dynamic virtual environments for industrial assemblies. Computers in Industry. Vol. 57, No. 4 (2006), pp. 366-377. ISSN 0166-3615

[41] Weidlich, D. et al. (2007) Virtual Reality Approaches for Immersive Design. CIRP Annals - Manufacturing Technology. Vol. 56, No. 1 (2007), pp. 139-142. ISSN 0007-8506

[42] Yang, R. D. et al. (2007) Virtual assembly Technologies based on constraint and DOF analysis. Robotics and Computer-Integrated Manufacturing. Vol. 23, No. 4 (2007), pp. 447-456. ISSN 0736-5845

[43] Zachmann, G. et al. (1999) Virtual reality as tool for verification of assembly and maintenance processes. Computers \& Graphics. Vol. 23, No. 3 (1999), pp. 389-403. ISSN 0097-8493 